\title{
Estamparia têxtil aplicada ao design de moda sustentável: caracterização do processo de gravação a laser em tecido de linho
}

Textile printing applied to sustainable fashion design: the process of laser engraving on linen

Letícia Formoso Assunção

Universidade Federal do Rio Grande do Sul

leticiafassuncao@gmail.com

Amalia Kusiak Martinez

Universidade Federal do Rio Grande do Sul

amaliakusiak@hotmail.com

Fernanda Xavier Marantes

Universidade Federal do Rio Grande do Sul

fermarantes@gmail.com

\author{
Lauren da Cunha Duarte \\ Universidade Federal do Rio Grande do Sul \\ lauren.duarte@ufrgs.br
}

Jocelise Jacques de Jacques

Universidade Federal do Rio Grande do Sul

jocelise.jacques@ufrgs.br

Gabriela Zubaran de Azevedo Pizzato

Universidade Federal do Rio Grande do Sul

gabriela.zubaran@ufrgs.br

\section{PROJËTICA}

\section{COMO CITAR ESTE ARTIGO:}

ASSUNÇÃO, Letícia Formoso; MARTINEZ, Amalia Kusiak; MARANTES, Fernanda Xavier; DUARTE, Lauren da Cunha; JACQUES, Jocelise Jacques de; PIZZATO, Gabriela Zubaran de Azevedo. Estamparia têxtil aplicada ao design de moda sustentável: caracterização do processo de gravação a laser em tecido de linho. Projética, Londrina, v. 12, n. 2, p. 262-291, 2021.

DOI: $10.5433 / 2236-2207.2021 v 12$ n2p262

Submissão: 14-04-2020

Aceite: 16-06-2020 
Estamparia têxtil aplicada ao... linho ASSUNÇÃO, L. F.; MARTINEZ, A. K.; MARANTES, F. X.; et al.

RESUMO: O presente artigo objetiva contribuir para o desenvolvimento de produtos de moda com menor impacto ambiental. Neste sentido, enfocamos o processo de gravação a laser no tecido de linho, buscando caracterizá-lo e padronizá-lo. Para tanto, são relatados ensaios de diferentes projetos gráficos com variação dos parâmetros potência e velocidade. Os resultados obtidos indicam parâmetros para a geração de estamparia por gravação a laser em linho que podem ser aplicados em escala industrial para produção de artigos de moda com características ambientalmente amigáveis.

Palavras-chave: Gravação a laser. Estamparia têxtil. Linho. Moda sustentável.

ABSTRACT: This article aims to characterize and standardize the laser engraving process on linen fabric for the development of fashion products under a sustainable approach. To do so, tests of different graphic projects are carried out with variation of the power and speed parameters. The results obtained indicate parameters for stamping by laser engraving on linen, which can be applied on industrial scale to produce fashion items with environmentally-sound characteristics.

Keywords: Laser engraving. Textile printing. Linen. Sustainable fashion.

\section{INTRODUÇÃO}

A indústria têxtil se caracteriza como uma das atividades de maior importância em escala global, contribuindo para o progresso das civilizações não somente em nível econômico, como também técnico e social. No Brasil, a produção atual do setor têxtil é relevante, obtendo o quinto lugar na fabricação mundial de tecidos e possuindo o quarto maior parque produtivo de confecções dentre todos os países (ASSOCIAÇÃO BRASILEIRA DA INDÚSTRIA TÊXTIL E DE CONFECÇÃO, 2018). No entanto, os processos de produção têxtil, confecção de vestuário e 
Projética, Londrina, v. 12, n. 2, p. 262-291, agosto 2021

beneficiamento de tecidos causam enormes impactos ao meio ambiente, pois consomem grandes volumes de recursos naturais, além de terem aspectos nocivos à saúde da população durante os processos produtivos' (SALCEDO, 2014).

Inovações tecnológicas têm atuado como importantes instrumentos na busca por manter o setor têxtil e de confecção competitivos frente ao mercado. Uma nova forma de comportamento tem emergido, fazendo com que estes setores, com auxílio da tecnologia, procurem soluções para mitigar os danos ambientais. Em todo o mundo, pesquisadores e empresas vêm unindo esforços na procura de processos produtivos eficientes e ambientalmente mais amigáveis (GWILT, 2014). Neste sentido, tornam-se relevantes estudos que apontam para esta direção, como os que analisam os tecidos com menos impactos negativos ao longo da cadeia produtiva e aqueles que investigam os processos de beneficiamento que contemplem características menos danosas.

Todo o processo de confecção do vestuário é complexo, com uma cadeia produtiva e de consumo espalhada globalmente. Neste cenário ambiental e socialmente problemático, pode ser mais eficaz endereçar esforços em partes do processo, como a estamparia que será o alvo deste artigo.O estudo desse processo específico de beneficiamento, sob o viés da sustentabilidade ambiental, justificase devido sua dimensão - uma vez que, em todo o mundo, estima-se que de 11 a $13 \%$ dos produtos têxteis sejam estampados - e em razão de suas difundidas formas de execução(como a serigrafia, a sublimação e a impressão digital a jato de

[1] Salcedo (2014) destaca que cerca de $20 \%$ de toda água contaminada que sai das indústrias do planeta é resultado apenas da indústria têxtil, a qual utiliza cerca de 390 bilhões de litros de água potável por ano. 0 mesmo setor é responsável igualmente por $10 \%$ das emissões de gás carbônico $\left(\mathrm{CO}_{2}\right)$. A autora aponta também as condições de trabalho insalubres e inseguras, sem contar o excesso de produtos tóxicos que afetam a saúde das pessoas que trabalham neste ramo. 
Estamparia têxtil aplicada ao... linho ASSUNÇÃO, L. F.; MARTINEZ, A. K.; MARANTES, F. X.; et al.

tinta)serem responsáveis por consideráveis danos ao meio ambiente, sobretudo pela utilização de água e produtos químicos em grande quantidade (SAXENA; RAJA; ARPUTHARAJ, 2017).

De acordo com Khan e Malik (2014), calcula-se que cerca de 128 mil litros de água são consumidos em processos de estamparia convencionais diariamente em uma fábrica têxtil de tamanho médio com produção de $8 \mathrm{mil} \mathrm{kg}$ de tecido por dia. Esse consumo elevado de água é atribuído, especialmente, à limpeza do maquinário e acessórios, à lavagem do tecido após a realização do processo de estamparia e às misturas químicas indicadas aos corantes e pigmentos. Os corantes e pigmentos utilizados para aplicações têxteis comerciais, por exemplo, são em sua maioria de origem sintética e apresentam baixa biodegradabilidade. Segundo Saxena, Raja e Arputharaj (2017), o corante não fixado nos produtos, que pode ser tóxico e cancerígeno, resulta em efluentes que têm um efeito altamente destrutivo aos ecossistemas aquáticos. Além disso, por não se degradarem nos processos convencionais de tratamento de efluentes, esses corantes tendem a ser separados como lodos sólidos e enviados para aterros, vindo a contaminar não somente as águas subterrâneas, mas também o solo.

Neste contexto, a inserção da tecnologia de gravação a laser em tecido de linho surge como uma possível alternativa no desenvolvimento de atividades inovativas relacionadas à sustentabilidade ambiental. O processo de gravação a laser se caracteriza como um procedimento tecnológico rápido e eficaz, com alto grau de detalhamento. Este processo de estamparia, por não envolver tinta ou água, possui pontos relevantes quanto à sustentabilidade ambiental (THOMPSON, 2011). No entanto, para que a fabricação de um produto de moda possa ser considerada ambientalmente amigável, é necessário também que a matéria-prima utilizada seja coerente com este objetivo. Nesta perspectiva, o linho - tecido proveniente do talo da planta de mesmo nome - é considerado um dos materiais têxteis mais alinhados com metas de baixo impacto, pois, quando cultivado em um local adequado, sua 
Projética, Londrina, v. 12, n. 2, p. 262-291, agosto 2021

planta não produz resíduos, dispensa irrigação em seu cultivo, pode reter 3,7 toneladas de $\mathrm{CO}_{2}$ por hectare ao ano, dentre outras características favoráveis ao meio ambiente.

Considerando o exposto, este artigo objetiva caracterizar e padronizar o processo de gravação a laser no tecido de linho para o desenvolvimento de produtos de moda sob enfoque da sustentabilidade ambiental. A partir da definição de parâmetros para este processo, pretende-se a verificação da sua viabilidade de aplicação em escala industrial, o que permitirá a ampliação do espectro de possibilidades de uso deste material. Esta pesquisa se fundamenta na percepção de lacunas referentes a temas pouco abordados em estudos científicos, como é o caso da utilização de laser para processos de gravação, e de projetos de estamparia têxtil em tecido de linho, os quais visem soluções inovadoras sob o aspecto socioambiental.

\section{LINHO}

O linho é uma planta herbácea da família das lináceas (Linum usitatissimum), composta por duas substâncias fundamentais, uma lenhosa em seu exterior e uma fibrosa em seu interior, da qual se extraem as fibras longas para a fabricação de tecidos. As fibras do linho são classificadas como fibras naturais de origem vegetal, extraídas a partir do talo da planta, podendo atingir até um metro de altura. Estas fibras geram tecidos que conseguem unir aspectos como conforto, durabilidade e versatilidade, além de terem capacidade de regular a temperatura do corpo em qualquer época do ano, possuírem propriedades antialérgicas, antibacterianas, não reterem poeira e serem resistente a traças e mofo (FARRER; WATT, 2015; FLETCHER, 2014). 
Conhecido como um dos tecidos mais antigos do mundo, o linho não tem sua origem bem definida, no entanto, foram encontrados indícios de fibras de linho datadas de aproximadamente 30.000 anos a.C. na caverna de Dzudzuana, localizada na Geórgia, país situado na fronteira entre a Europa e a Ásia. Estas fibras estavam torcidas e algumas delas tingidas, levando os pesquisadores a acreditarem que estas descobertas representaram a produção de têxteis para algum propósito da época. Além destes indícios, existem registros de 2.500 anos a.C que comprovam que o linho era cultivado pelos egípcios, sendo utilizado tanto para enrolar suas múmias, quanto para confecção de roupas finas usadas como instrumentos de expressão de classes sociais. Ademais, existem inúmeras alusões ao linho em relatos bíblicos, dentre elas a menção de que Jesus Cristo teria sido sepultado com uma peça produzida inteiramente com este tecido (KVAVADZE, 2009).

A fabricação de linho foi muito difundida nos países europeus até o final do século XVIII, porém, a partir da Revolução Industrial, a fibra de linho começou a perder participação de mercado e popularidade à medida que era substituída por fibras sintéticas mais resistentes ao vinco e com produção em massa de baixo custo, como o poliéster. No entanto, na última década "uma visão contemporânea do linho está surgindo [...] respondendo às necessidades de uma nova geração de consumidores que buscam qualidade, habilidade e benefícios sociais" (FARRER; WATT, 2015, p. 24). Atualmente, o linho permanece sendo um símbolo de status pelo seu valor de comercialização e superioridade na durabilidade, sofisticação e sustentabilidade ambiental em relação a outros tecidos naturais, como o algodão.

Quanto ao seu viés sustentável, enfocando o pilar ambiental, o linho pode ser considerado uma fibra orgânica, pois sua produção natural não requer pesticidas, irrigação artificial ou fertilizantes. Os recursos naturais são suficientes para alimentar a planta, que deve ser cultivada em climas temperados e tem a reputação de excelente fertilizante do solo. Em comparação com o algodão, por exemplo, o linho requer cinco vezes menos inserção na terra, preservando a qualidade da água 
Projética, Londrina, v. 12, n. 2, p. 262-291, agosto 2021

subterrânea. A planta é também um sumidouro de carbono visto que, durante o seu crescimento, a produção de linho absorve uma expressiva quantidade de $\mathrm{CO}_{2}$ liberado para a atmosfera (o linho absorve mais dióxido de carbono na fase de crescimento do que libera durante o processamento). Caracteriza-se por ser uma fibra reciclável, biodegradável e de desperdício zero, onde tudo é usado ou processado (as plantas de linho fornecem subprodutos valiosos, como sementes, ceras, fragrâncias e pigmentos, que podem ser usados como alimentos, forragem, produtos farmacêuticos, cosméticos e itens de higiene corporal). Além disso, os processos de fiação e tecelagem possuem impacto praticamente nulo (FARRER; WATT, 2015; FLETCHER, 2014).

Contudo, existem desvantagens técnicas e certas dificuldades a serem enfrentadas no uso de tecidos 100\% linho, que incluem: a sua aparência irregular, a transparência relativa causada pela falta de massa em seus fios, a baixa resistência ao vinco que apresenta em condições secas e úmidas, além de, em termos de custo, ser uma matéria-prima de preço elevado² (HANN, 2005; SALMON-MINOTTE; FRANCK, 2005). As questões referentes à estética do tecido de linho, sendo de natureza subjetiva, podem ser ressignificadas e consideradas atributos positivos a partir do interesse do mercado de moda de estabelecer novos padrões de gosto. Já em relação ao seu alto custo, torna-se necessário tornar o linho uma matériaprima atraente também do ponto de vista da sustentabilidade econômica, por meio de produtos mais longevos, que são adquiridos para durarem mais. O tecido de

[2] Salmon-Minotte e Franck (2005) destacam que o tecido de linho possui um preço mais elevado em comparação a outros tecidos como algodão, poliéster e viscose, por diversas razões, que abrangem: a produção da fibra de linho exigir operações complexas e trabalhosas em termos de mão de obra; o seu fio ter menor eficiência de fiação (o tamanho relativamente pequeno da indústria do linho desencoraja os fabricantes de máquinas têxteis a desenvolverem máquinas especificamente para essa fibra); e a escala reduzida da sua indústria, que afeta não somente a fiação, mas outras operações de fabricação e varejo. 
linho permite que seja estendido o tempo de vida útil de seus produtos, pois possui alta resistência à tração, é resistente ao desgaste (sendo a fibra têxtil natural mais forte e duradoura) e melhora seu aspecto tátil à medida que envelhece ${ }^{3}$. Neste viés, segundo Farrer e Watt (2015, p. 36), do ponto de vista da sustentabilidade ambiental, o uso do linho deve ser estimulado, uma vez que "o material pode biodegradar quando não for mais necessário ou sobreviver por séculos, caso a aplicação exija".

\section{PROCESSO DE GRAVAÇÃO A LASER}

O laser (abreviação de Light Amplified by Stimulated Emission Radiation) é um instrumento de altíssima precisão geométrica, rapidez e eficácia, que tem seu funcionamento baseado nas leis fundamentais da interação entre a radiação luminosa e a matéria. Segundo Thompson (2011), o laser é certamente uma das maiores invenções do século XX, emergindo como uma atrativa ferramenta que se destaca pela diversidade de aplicações nas mais diversas áreas do conhecimento técnico e científico.

A utilização da tecnologia a laser tem sido gradualmente utilizada industrialmente para a produção de têxteis e vestuário desde que foi desenvolvida em $1960^{4}$. Em virtude de sua precisão para marcação e corte de superfícies,

[3] Quanto mais é lavado, mais o fio de linho melhora em flexibilidade e suavidade, pois a pectina que liga as fibras na fase de crescimento se dissolve em contato com a água. Portanto, conforme as lavagens, o tecido de linho se torna gradualmente um material mais confortável à medida que envelhece (FARRER; WATT, 2015).

[4] A primeira demonstração de um laser ocorreu em um laboratório de pesquisa na Califórnia em maio de 1960 e os sistemas começaram a ser fabricados comercialmente no final da década de 1960. O laser de $\mathrm{CO}_{2}$, atualmente utilizado na indústria atualmente para o processamento de têxteis, foi desenvolvido em 1964, em Nova Jersey, passando a ser comercializado dois anos depois (MATTHEWS, 2011). 
Projética, Londrina, v. 12, n. 2, p. 262-291, agosto 2021

essa tecnologia, de acordo com Yuan, Chen e Luzzi (2018), revolucionou os campos relacionados da ciência e da tecnologia. No contexto atual, o laser é uma ferramenta indispensável para uma variedade de processos de fabricação, como remoção de material, aquecimento de superfície, dobra, texturização, rugosidade e marcação (YUAN et al., 2013). Na indústria da moda, a tecnologia a laser vem sendo amplamente aplicada nos cortes de tecido, por ser uma técnica precisa e limpa, e no acabamento de peças em jeans ${ }^{5}$, em que é utilizada para remover seletivamente o corante índigo sintético da superfície do tecido, gerando efeitos estéticos de desgaste e desbotamento.

A marcação e gravação das tecnologias a laser podem ser usadas para diferentes aplicações. Dependendo da função a que se destinam, as imagens são decorativas e informativas (a partir de referências técnicas como símbolos, código de barras, números de série e logotipos). Em relação às superfícies de interação, a tecnologia pode ser utilizada em inúmeros materiais, incluindo plástico, metal, cerâmica, vidro, madeira e substratos têxteis, como couro, algodão, jeans, poliéster, linho, entre outros (YUAN; CHEN; LUZZI, 2018). Como desvantagens, a técnica apresenta a dificuldade de gravação de linhas muito aproximadas, pois essas tendem a se unir, e a impossibilidade de gravação colorida, apenas com uma escala tonal que compreende tons terrosos ou uma variação que vai do branco ao preto, passando por tonalidades de cinza (MATTHEWS, 2011).

[5] O processo de gravação a laser em peças de jeans oferece uma alternativa às técnicas de jateamento de areia, lavagem ácida ou com pedras-pome, reduzindo significativamente a perda de resistência do tecido e os problemas ambientais associados a essas técnicas convencionais (YUAN; CHEN; LUZZI, 2018). 
No tocante ao seu modo de funcionamento, a tecnologia de gravação a laser se dá através de milhões de pontos que unidos reproduzem a forma do objeto a ser gravado, em que o feixe de luz causa no material: vaporização, remoção de camadas finas, carbonização e modificação da superfície por fusão do material. Conforme Bagnato (2008), a qualidade de uma gravação é avaliada através de suas características de legibilidade, como o contraste, a largura e a profundidade da marcação. Tendo em vista estes aspectos, a fim de obter-se uma gravação clara, parâmetros de processamento adequados devem ser selecionados para materiais distintos.

Esta técnica possui a vantagem de produzir uma gravação permanente de alta qualidade, velocidade e precisão, com baixo custo de operação, uma vez que a tecnologia não requer produtos especiais de preparação ou acabamento (apenas necessitando da aquisição do equipamento, manutenção do mesmo e uso de luz elétrica ${ }^{6}$ ) (MATTHEWS, 2011). Além disso, o laser é um equipamento fácil de automatizar e integrar, é capaz de gravar em superfícies irregulares, possui alta reprodutibilidade e é livre de contaminação (HAN; GUBENCU, 2008). Neste sentido, o processo de gravação a laser surge como uma alternativa de produção mais eficiente e menos agressiva ao meio ambiente, sem que haja perda de competitividade de mercado e produtividade.

[6] Um equipamento a laser com potência de 80 watts, possui um consumo de energia de aproximadamente $50 \mathrm{kWh}$ por mês, o que corresponde ao consumo de cerca de 2 computadores de escritório (TROTEC, 2020). 
Projética, Londrina, v. 12, n. 2, p. 262-291, agosto 2021

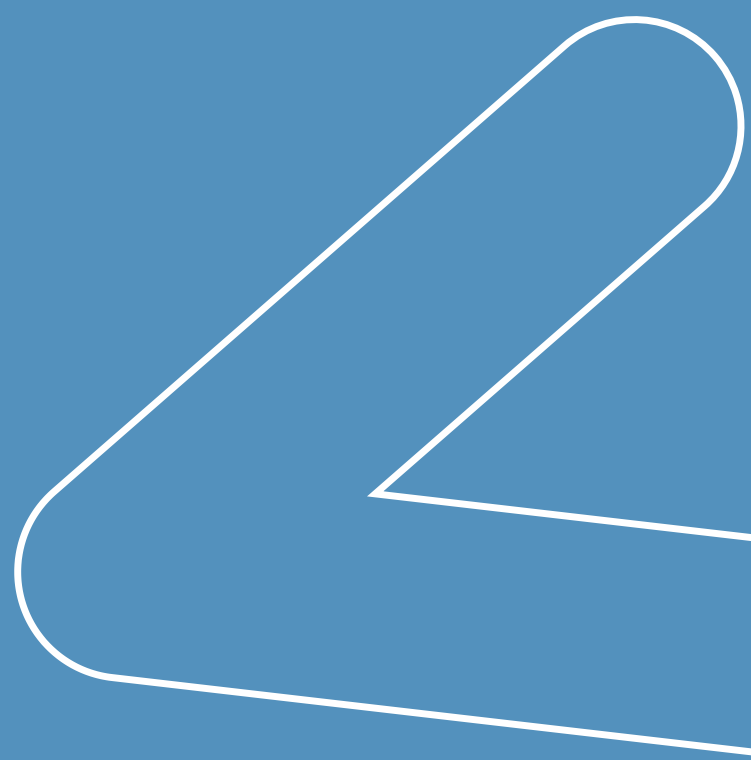

O processo de gravação a laser surge como uma alternativa de produção mais eficiente e menos agressiva ao meio ambiente, sem que haja perda de competitividade de mercado e produtividade.
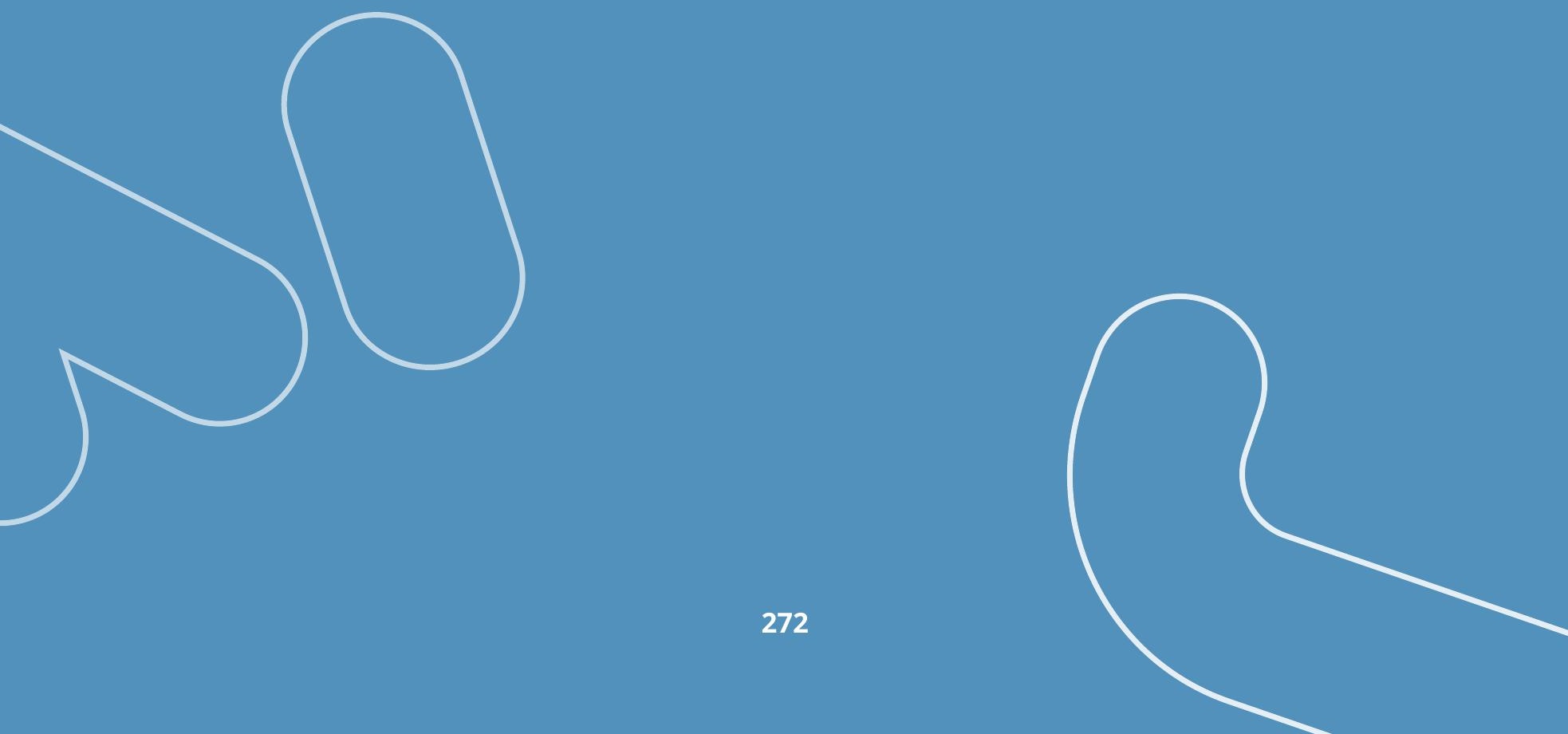
Yuan et al. (2013) expõem que o laser é, atualmente, o instrumento que proporciona menor impacto ambiental em relação a processos de estamparia têxtil, quando comparado a outras formas de impressão a base de pigmentos ${ }^{7}$. Os autores ainda apontam que a eficiência energética e a velocidade de operação de uma fonte de laser são superiores a qualquer outra técnica de produção tradicional. Segundo eles, "a tecnologia a laser proporciona um impacto ambiental significativamente benéfico, pois elimina tintas, produtos químicos e solventes" (YUAN et al., 2013, p. 21). Além disso, como um processo controlado, possui alta velocidade de processamento, gera pouco desperdício na etapa pré-produção (não necessita de papel ou forma), opera com precisão, requer menos energia e não necessita de água. Todos estes benefícios demonstram que a tecnologia de gravação a laser, como uma tecnologia seca e limpa, é altamente eficaz no tratamento de superfícies de produtos de moda (YUAN et al., 2013).

\section{MATERIAIS E MÉTODOS}

Para esta pesquisa, no que se refere ao material a ser estudado, foi utilizado tecido de linho puro em seu estado cru, com 0,4mm de espessura, adquirido no comércio em Porto Alegre/RS. Optou-se pelo linho sem tingimento, pois além de ter

[7] Realizada nas formas tradicionais, a etapa de beneficiamento têxtil - chamada de estamparia - consome grandes volumes de recursos naturais e de produtos químicos nocivos ao meio ambiente e à saúde do prestador de serviço. Os processos de estamparia mais usados atualmente na indústria têxtil (serigrafia e estamparia digital: sublimação e impressão a jato de tinta), utilizam diversos corantes, pigmentos e tintas com alto caráter poluidor e toxicológico. Além disso, fazem uso elevado de energia nas etapas de lavagem e produção, a liberação de produtos químicos, que podem ser percebidos no meio ambiente através da contaminação do solo, do ar e da água. A poluição do solo se dá basicamente pela geração de resíduos como restos de pasta de estampar, telas e embalagens como principais poluidores. Já a poluição do ar, pelas emissões atmosféricas, como gases de combustão e vapores de solventes. E a poluição da água, na geração de efluentes provenientes da lavagem do material do processo, como telas e rodo, maquinário e piso, além do produto já estampado (BLACKBURN, 2009). 
Projética, Londrina, v. 12, n. 2, p. 262-291, agosto 2021

pegada ecológica menor em relação aos tecidos coloridos artificialmente, é também o mais utilizado para fins comerciais. Deste material foram utilizadas amostras compatíveis com as lentes do instrumento de laser tendo área de trabalho de $30 \mathrm{x}$ $30 \mathrm{~cm}$, além de amostras de $30 \times 2,5 \mathrm{~cm}$ adequadas às normas do ensaio de tração (ASSOCIAÇÃO BRASILEIRA DE NORMAS TÉCNICAS, 2016).

Para a realização dos testes de interação entre o laser e o tecido de linho, utilizou-se o equipamento de corte e gravação de modelo Mira 3007, Automatisa Sistemas Ltda ${ }^{\circledR}$, localizado no Laboratório de Design e Seleção de Materiais (LdSM) da Universidade Federal do Rio Grande do Sul (UFRGS). O equipamento é do tipo galvanométrico e possui uma fonte de laser fixa. O meio ativo para geração de radiação é gasoso, do tipo $\mathrm{CO}_{2}$ e, para este estudo, foi utilizada a lente para área de trabalho de $30 \mathrm{~cm} \times 30 \mathrm{~cm}\left(900 \mathrm{~cm}^{2}\right)$, tendo em vista a possibilidade de produções de peças de vestuário tanto de estampas localizadas quanto de estampas corridas ${ }^{8}$. Além das lentes, as variáveis passíveis de ajuste no equipamento são a potência (W) e a velocidade ( $\mathrm{m} / \mathrm{min}$ ). Este equipamento de laser, que opera com objetos gráficos do tipo vetorial e de imagem, é controlado via computador por meio de comandos do software LaserDraw ${ }^{\circledR}$, o qual orienta o feixe a percorrer uma trajetória nos eixos $x$ e y construindo um desenho bidimensional.

Com base nestas informações, para este estudo foram criados desenhos no programa CorelDRAW X4® (software de desenho vetorial bidimensional) salvos em extensão.plt (arquivo de plotadora HPGL) e .jpg (bitmaps JPEG), visando caracterizar as marcações a laser em tecido de linho. Primeiramente, foram criados desenhos de formas retas, a fim de testar diferentes parâmetros de potência e velocidade e verificar os resultados mais satisfatórios. Para isto, foram utilizados 07 traços retos simples espaçados $(1,0 \mathrm{~cm})$ com diferentes velocidades, em extensão

[8] Estampas localizadas se referem a estampas fixas em determinados locais da peça. Já as estampas corridas representam uma sequência de padrões que preenchem toda área da superfície do tecido (VIEIRA, 2014). 
.plt. Em seguida, foram criadas linhas retas para a qualificação de espaçamentos entre os traços (com distâncias de 1,5; 1,0;0,5mm) em arquivo com extensão .plt, para identificar a espessura da zona de influência do laser no material e verificar a possível interação entre as linhas. Posteriormente, para observar a resolução de curvatura do traçado em formas arredondadas, foi criado um desenho de linhas curvas, caracterizando uma estampa floral, salvo em extensão .plt e .jpg.

Para a realização dos ensaios de tração em linho gravado a laser, com o elemento sendo o de um círculo de $1,5 \mathrm{~cm}$ de diâmetro localizado no centro de cada corpo de prova, para testar como estampas localizadas se comportariam em relação a esforços de tração. A margem sem gravação nos quatro lados do desenho com as seguintes medidas: superior e inferior com $14,25 \mathrm{~cm}(47,5 \%)$ e margens laterais com $0,5 \mathrm{~cm}(20 \%)$.

Finalmente, a fim de analisar as variações de tonalidades, foram desenhados 05 retângulos, salvos na extensão .jpg, com resolução de 200 dpi., configurados em porcentagens de saturação de preto decrescendo de 20 em 20\%. Após definidos os melhores parâmetros de variações de tonalidades, foi utilizada uma padronagem semelhante a uma mandala com diferentes tons de cinza (100, 60 e 40\% de saturação) para constatar a efetividade de gravação e compor distintas combinações visando criar um efeito de gradiente visualmente adequado.

No intuito de examinar e analisar as amostras de tecido de linho gravadas a laser, inicialmente foi realizada uma inspeção visual e tátil. Este método, embora empírico, é de extrema importância, pois o aspecto estético a vista desarmada é fator determinante na obtenção dos resultados mais satisfatórios. A fim de caracterizar a interação entre o laser e o material, utilizou-se o Microscópio Eletrônico de Varredura (MEV), de modelo Hitachi TM 3000, com detector de elétrons retroespalhados que gera imagens eletrônicas, pertencente ao LdSM/UFRGS, para geração de imagens do tipo BSE (backscaterred electron). A aceleração do feixe de elétrons utilizada foi de $15 \mathrm{KeV}$ e a magnificação da ordem de 40 e 800 vezes. Além 
Projética, Londrina, v. 12, n. 2, p. 262-291, agosto 2021

disso, para as análises visuais das superfícies gravadas, foi utilizado o Microscópio Estereoscópico SZX16, da marca Olympus, também pertencente ao LdSM/UFRGS. A visualização das imagens geradas é realizada pelo software AnalySIS Starter. Nesta etapa foram utilizados aumentos entre 0.7 e 1.25x.

Os ensaios de tração foram feitos para avaliar a resistência do tecido de linho após ser gravado. Foi utilizado o equipamento universal de ensaios de tração e compressão da marca Shimadzu, modelo EZ-LX, localizado na Oficina de Modelos e Protótipos da Faculdade de Arquitetura da Universidade Federal do Rio Grande do Sul (UFRGS). Para quantificar o momento de rompimento do tecido de linho, foram utilizados 15 corpos de prova medindo $30 \times 2,5 \mathrm{~cm}$ cada, cortados no sentido do urdume, os quais foram fixados pelas suas extremidades nas garras da máquina. Primeiramente, foram testadas 06 amostras: 03 sem gravação e 03 com estampas corridas gravadas a laser com potência de 100\% (43W) e velocidade $20 \mathrm{~m} / \mathrm{min}$. Em um segundo teste, foram sujeitos aos ensaios de tração09 corpos de prova: 03 sem gravação, 03 com estampas localizadas gravadas com potência 100\% ( 43 W) e velocidade $20 \mathrm{~m} / \mathrm{min}$, e 03 também gravados com estampa localizada, mas com potência $50 \%(\sim 21,5 \mathrm{~W})$ e velocidade $10 \mathrm{~m} / \mathrm{min}$.

\section{RESULTADOS E DISCUSSÕES}

A gravação no tecido de linho ocorre por carbonização localizada, a qual produz uma marcação monocromática de coloração marrom devido ao aquecimento do material. As dimensões e a distribuição da queima gerada no tecido são resultantes das variações de velocidades e potências submetidas às amostras. Com o objetivo de eleger os parâmetros mais legíveis, primeiramente foram realizadas gravações de linhas retas com diferentes variáveis. Neste momento, foram utilizadas as velocidades de 1, 5, 10, 20, 30, 40 e 50m/min testadas em duas diferentes potências: 100\% (aproximadamente 46W) e 50\% (aproximadamente 23W) (figura 1). 
Figura 1 - Testes de gravação em tecido de linho cru com potências de 100\% (amostra A com velocidades de 1, 5, 10, 20, 30, 40 e 50m/min); e 50\% (amostra B com velocidades de 1, 5, 10, 20, 30 e 40 m/min) (LDSM/UFRGS).
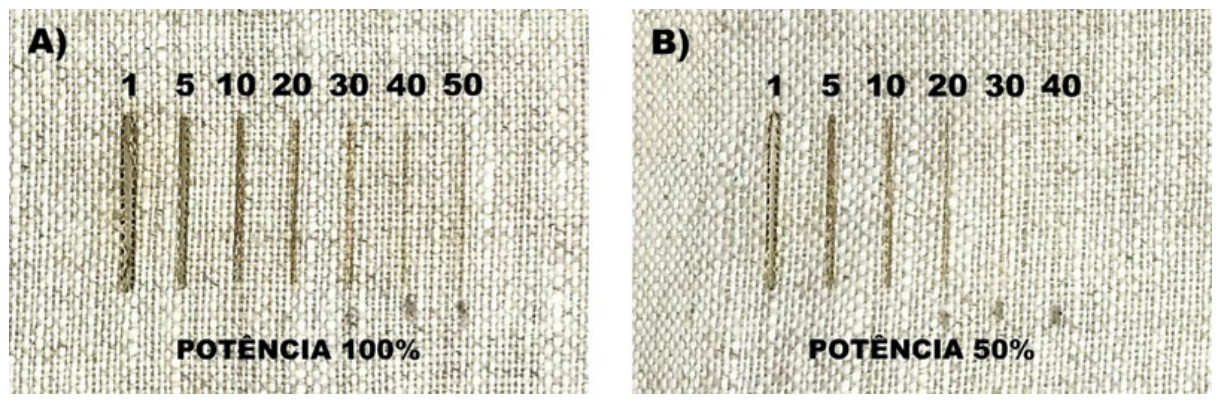

Fonte: Elaborado pelas autoras (2018).

Com a realização deste ensaio, percebeu-se que nas gravações com velocidades menores (1 e $5 \mathrm{~m} / \mathrm{min}$ ) o tecido foi rompido, não interessando a potência. Na velocidade de $10 \mathrm{~m} / \mathrm{min}$ e potência de $100 \%$ o tecido não chega a romper, mas fica extremamente frágil. Os resultados mais satisfatórios foram nas gravações com potência de $100 \%$ e velocidade de $20 \mathrm{~m} / \mathrm{min}$, e potência $50 \%$ e velocidade $10 \mathrm{~m} /$ min, que produziram tonalidade levemente mais fraca em relação às primeiras. Com o aumento da velocidade de varredura do laser, a gravação passa a ocorrer de forma mais superficial. Para as velocidades de 30, 40 e $50 \mathrm{~m} / \mathrm{min}$ com potência de $100 \%$, e para velocidades de $20,30,40 \mathrm{~m} / \mathrm{min}$ com potência de $50 \%$, o feixe do laser degradou superficialmente a amostra, resultando em linhas de tonalidades claras e pouco aparentes. A gravação com potência de $50 \%$ e velocidade de $50 \mathrm{~m} / \mathrm{min}$ não possibilitou a visualização da linha tanto à vista desarmada quanto via microscópio estereoscópico (figura 2). 
Projética, Londrina, v. 12, n. 2, p. 262-291, agosto 2021

Figura 2 - Imagens obtidas no microscópio estereoscópico dos testes executados em tecido de linho cru com potências de 100\% (amostra Acom velocidades de 1, 5, 10, 20, 30, 40 e 50m/min); e 50\% (amostra Bcom velocidades de 1, 5, 10, 20, 30 e $40 \mathrm{~m} / \mathrm{min}$ ) (LDSM/UFRGS).
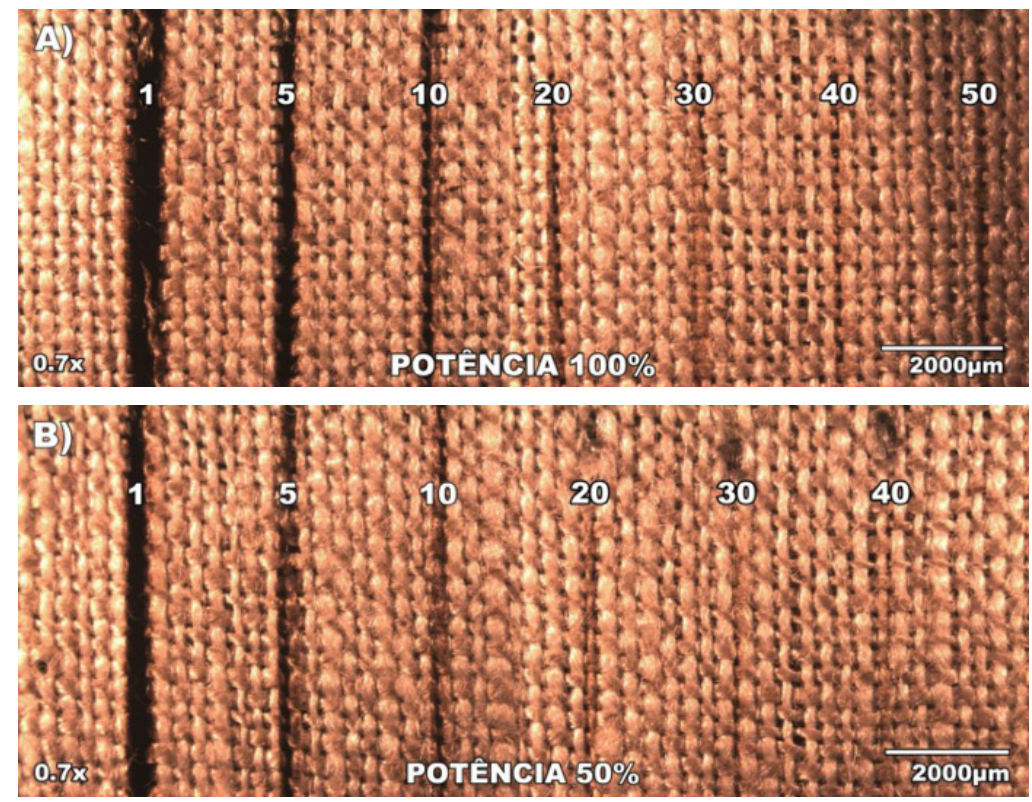

Fonte: Elaborado pelas autoras (2018).

Ao obter imagens eletrônicas por Microscópio Eletrônico de Varredura (MEV), pode-se observar como o laser afetou as fibras do linho (Figuras 3,4). Em conformidade com os resultados de Ferrero et al. (2002) a degradação aumentou conforme o aumento da potência. Além disso, o feixe do laser degradou termicamente as fibras e rompeu o tecido em velocidades mais baixas, como descrito anteriormente. Nas imagens é possível perceber que, mesmo em velocidades médias e altas, o feixe permaneceu degradando algumas fibras do material, mas de forma superficial. No entanto, na potência de 50\%, mesmo com magnificação de 100 vezes, não foi possível perceber alteração nas fibras do tecido nas velocidades de 40 e $50 \mathrm{~m} / \mathrm{min}$. 
Figura 3 - Imagens eletrônicas de varredura obtidas no MEV dos testes executados em tecido de linho cru com potência de 100\% (LDSM/UFRGS). Amostra: A) velocidade $1 \mathrm{~m} / \mathrm{min}$; B) velocidade $5 \mathrm{~m} / \mathrm{min}$; C) velocidade $10 \mathrm{~m} / \mathrm{min}$; D) velocidade $20 \mathrm{~m} / \mathrm{min}$; ) velocidade $30 \mathrm{~m} / \mathrm{min}$; F) velocidade $40 \mathrm{~m} / \mathrm{min}$; G) velocidade $50 \mathrm{~m} / \mathrm{min}$. As sinalizações com linhas pontilhadas amarelas destacam as degradações térmicas ocorridas nas fibras de linho nas diferentes amostras.

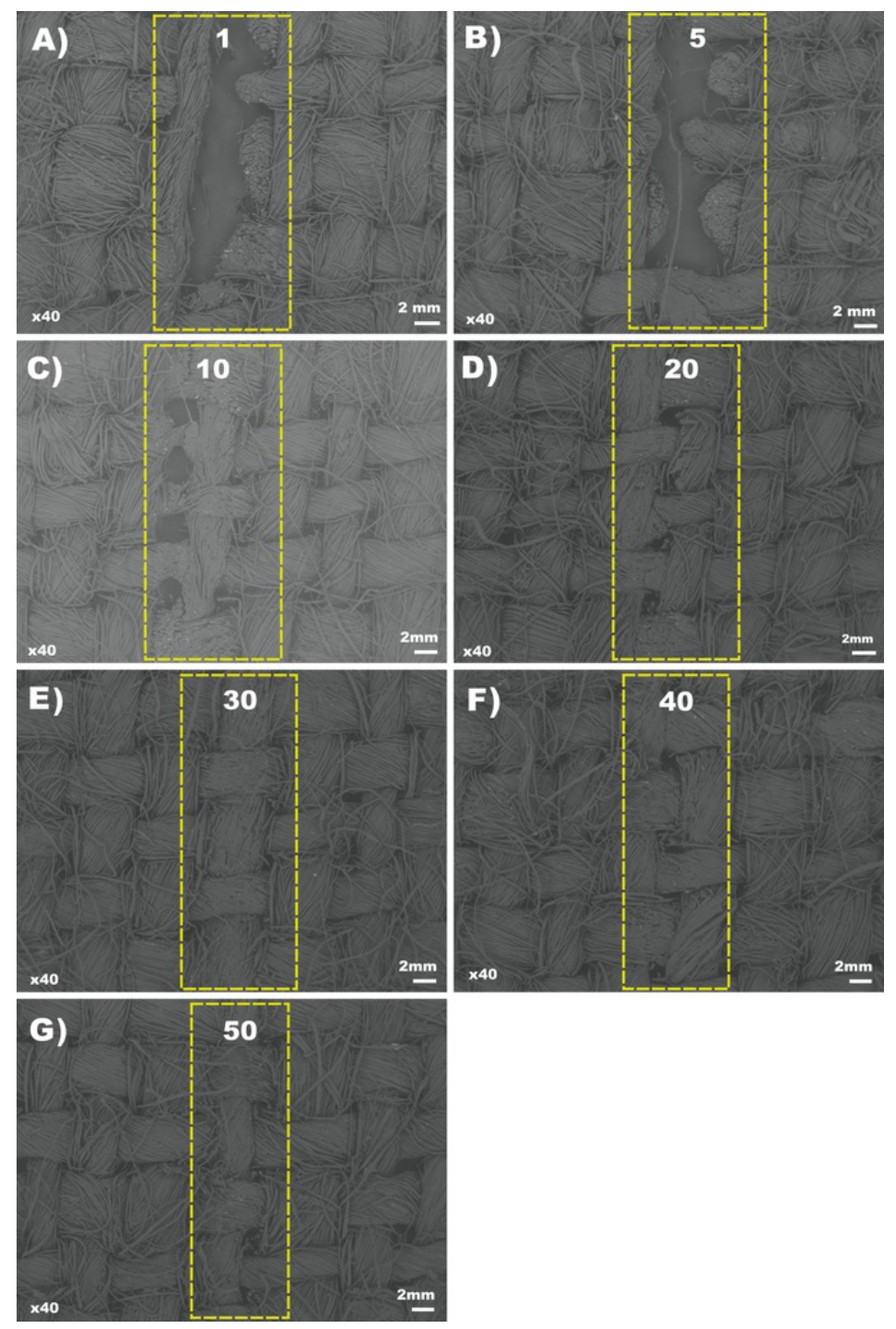

Fonte: Elaborado pelas autoras (2018). 
Projética, Londrina, v. 12, n. 2, p. 262-291, agosto 2021

Figura 4 - Imagens eletrônicas de varredura obtidas no MEV dos testes executados em tecido de linho cru com potência de 50\% (LDSM/UFRGS). Amostra: A) velocidade $1 \mathrm{~m} / \mathrm{min}$; B) velocidade $5 \mathrm{~m} / \mathrm{min}$; C) velocidade $10 \mathrm{~m} /$ $\mathrm{min}$; D) velocidade $20 \mathrm{~m} / \mathrm{min}$; E) velocidade $30 \mathrm{~m} / \mathrm{min}$. As sinalizações com linhas pontilhadas amarelas destacam as degradações térmicas ocorridas nas fibras de linho nas diferentes amostras.
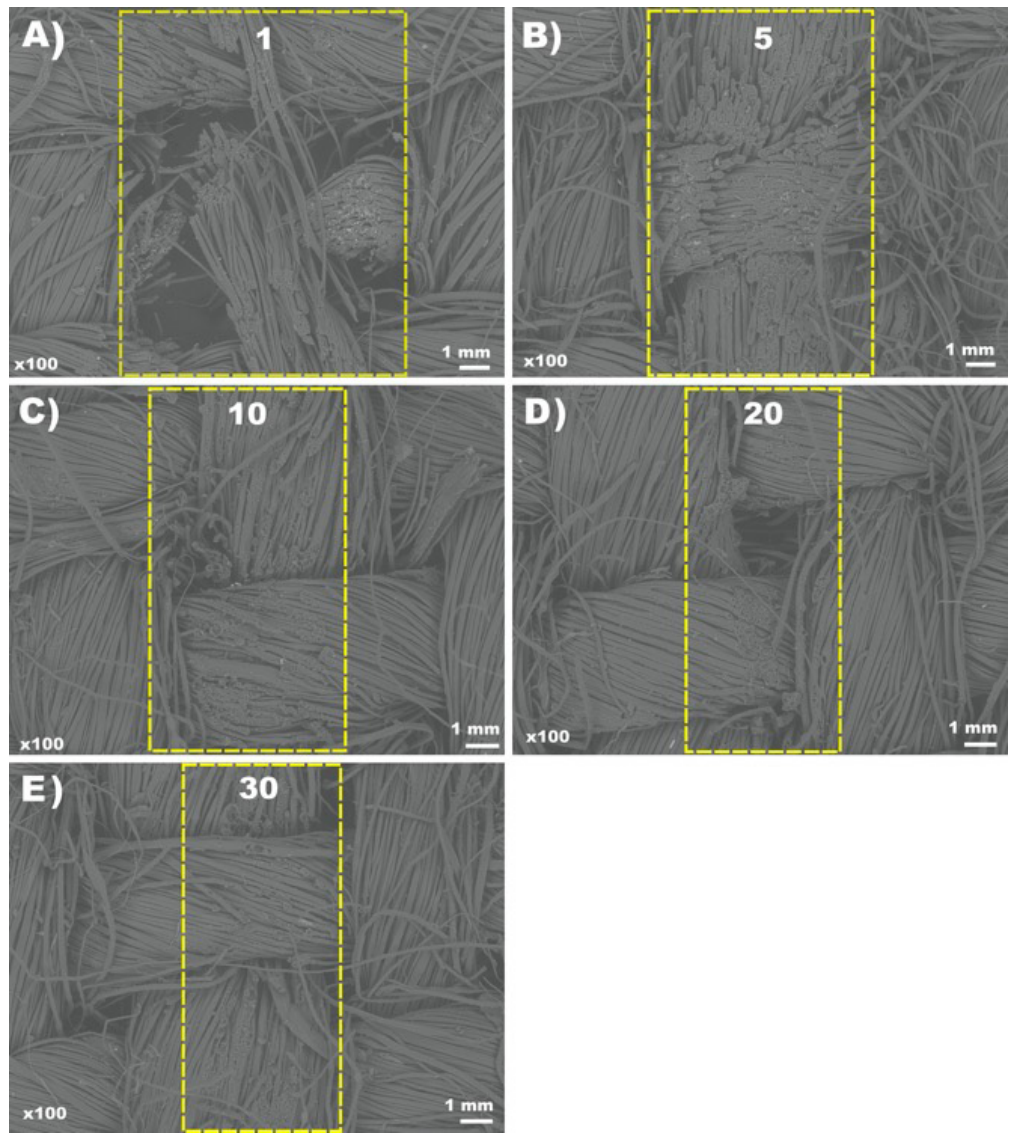

Fonte: Elaborado pelas autoras (2018).

Com base nos resultados mais satisfatórios destas análises, definiram-se os seguintes parâmetros de utilização para gravação a laser no tecido de linho cru: potência de $100 \%$ com velocidade $20 \mathrm{~m} / \mathrm{min}$, e potência de $50 \%$ com velocidade $10 \mathrm{~m} / \mathrm{min}$. Com estas variáveis eleitas, seguiu-se para os demais testes. 
Estamparia têxtil aplicada ao... linho ASSUNÇÃO, L. F.; MARTINEZ, A. K.; MARANTES, F. X.; et al.

Para análise da relação dos espaçamentos entre linhas foi realizada a gravação de traços retos aproximados $(1,5 ; 1,0$ e 0,5mm) utilizando potência de $100 \%$ e velocidade $20 \mathrm{~m} / \mathrm{min}$, conforme é possível observar na Figura 5:

Figura 5 - Testes de gravação a laser de espaçamento entre linhas com potência de 100\% e velocidade de 20m/min (LDSM/UFRGS). Distâncias entre as linhas:1,5mm; $1,0 \mathrm{~mm} ; 0,5 \mathrm{~mm}$.

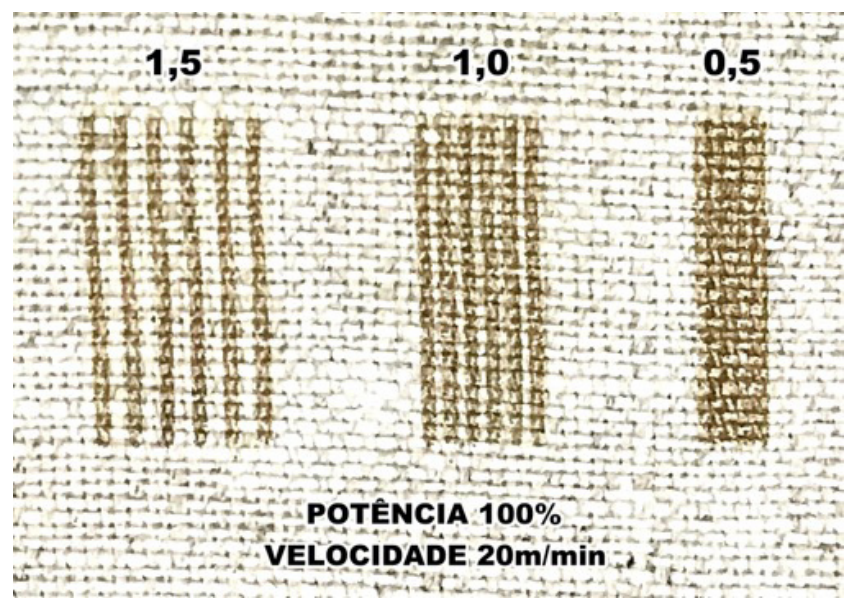

Fonte: Elaborado pelas autoras (2018).

Os resultados analisados por microscópio estereoscópico das linhas gravadas com os espaçamentos referidos delimitam a zona de influência da interação do feixe laser com o tecido. Com base no que foi observado, os desenhos criados para a utilização de gravação a laser em linho deverão conter os espaçamentos entre as linhas iguais ou maiores que $1 \mathrm{~mm}$, a fim de evitar que os traços se unifiquem pela proximidade. As distâncias iguais ou menores que $0,5 \mathrm{~mm}$ podem servir, desta maneira, para desenhos em formato .plt que necessitem de preenchimento (figura 6). 
Projética, Londrina, v. 12, n. 2, p. 262-291, agosto 2021

Figura 6 - Imagens obtidas no microscópio estereoscópico dos testes de espaçamento entre linhas com potência de $100 \%$ e velocidade de $20 \mathrm{~m} / \mathrm{min}$ (LDSM/ UFRGS). Distâncias entre as linhas: A) 1,5mm; B) 1,0mm; C) 0,5mm.

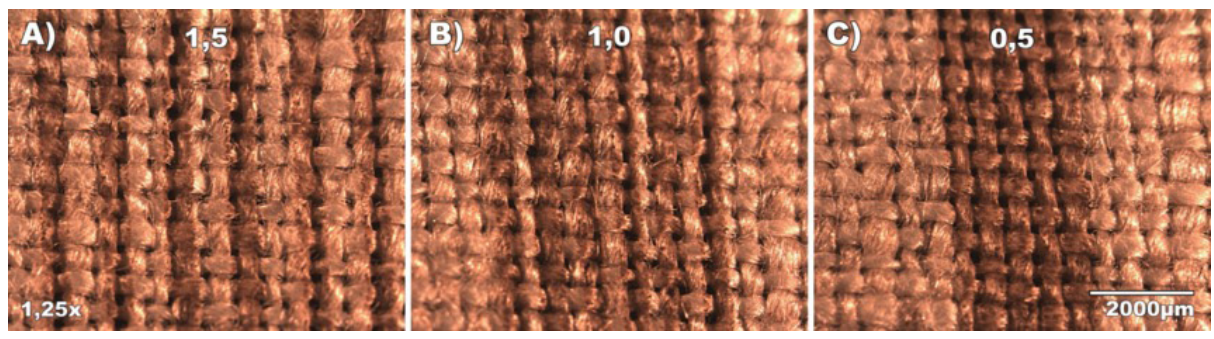

Fonte: Elaborado pelas autoras (2018).

Com base nestes resultados, seguiu-se para um exemplo de aplicação de uso em estampas para peças de vestuário, com dimensões de $30 \times 30 \mathrm{~cm}$. Para tal, foi gravada uma estampa com motivos florais, contendo traços curvos em potência de $100 \%$ e velocidade de $20 \mathrm{~m} / \mathrm{min}$, que pode ser visualizada na figura 7 :

Figura 7 - Teste de aplicabilidade da gravação a laser em estamparia têxtil com potência de $100 \%$ e velocidade de $20 \mathrm{~m} / \mathrm{min}$ (LDSM/UFRGS).

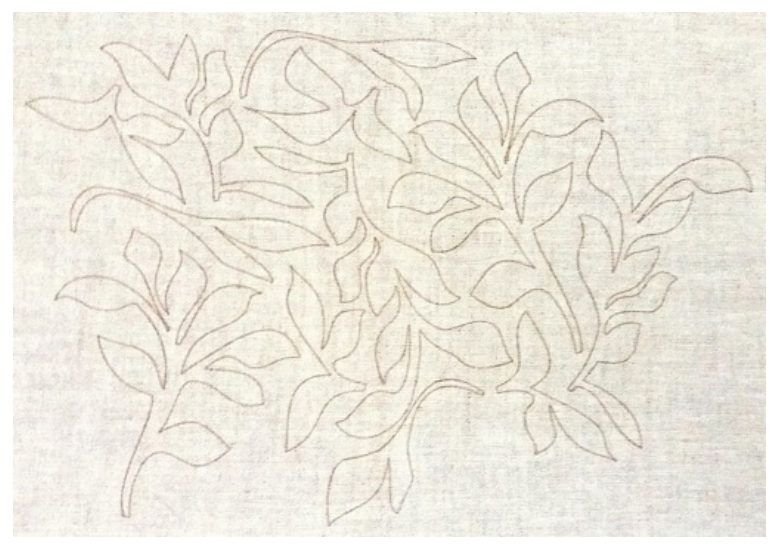

Fonte: Elaborado pelas autoras (2018). 
A seguir, para compreensão do efeito de diferentes saturações tonais, foram gravadas cinco porcentagens diferentes de tons de cinza $(100,80,60,40$ e $20 \%$ ) com potência $100 \%$, velocidade máxima de $152 \mathrm{~m} / \mathrm{min}$, velocidade mínima de $40 \mathrm{~m} / \mathrm{min}$ e resolução de $200 \mathrm{dpi}$ (figura 8).

Figura 8 - Teste de gravação a laser de escala tonal com potência de 100\%, velocidade máxima de $152 \mathrm{~m} / \mathrm{min}$, velocidade mínima de $40 \mathrm{~m} / \mathrm{min}$ e resolução de 200dpi (LDSM/UFRGS).

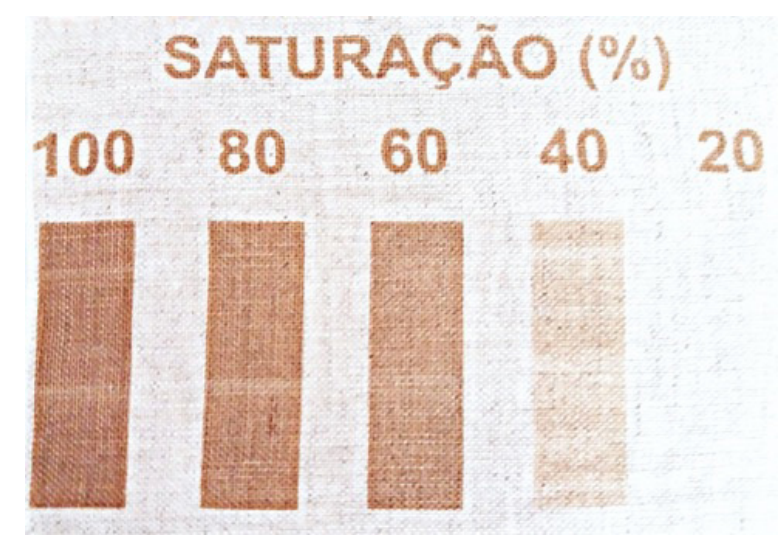

Fonte: Elaborado pelas autoras (2018).

Os resultados deste teste mostraram que as qualidades visuais relativas aos valores de 80 e 60\% ficaram semelhantes sendo, assim, possível obter 03 saturações visualmente distintas nas gravações a laser em tecido de linho: uma forte (100\%), uma mediana (80 ou 60\%) e uma fraca (40\%). Em relação à saturação tonal de $20 \%$, esta não gerou a gravação do material, não obtendo nenhum efeito visual ou tátil, devendo ser desconsiderada. Embora o processo de gravação a laser permita apenas marcações monocromáticas - no caso do tecido de linho, somente em tons de marrom - ao estabelecer estes valores de saturação, aumenta-se a 
Projética, Londrina, v. 12, n. 2, p. 262-291, agosto 2021

possibilidade de criação de desenhos e estampas, tornando possível a produção de diversos efeitos, como o de profundidade e o degradê. Com a finalidade de demonstrar a utilização dos diferentes tons em uma mesma figura, gravou-se a imagem de uma mandala contendo as saturações de 100, 60 e 40\% (figura 9).

Figura 9 - Teste de aplicabilidade de escala tonal (100, 60 e 40\%) com potência de $100 \%$ e velocidade de $20 \mathrm{~m} / \mathrm{min}$ (LDSM/UFRGS).
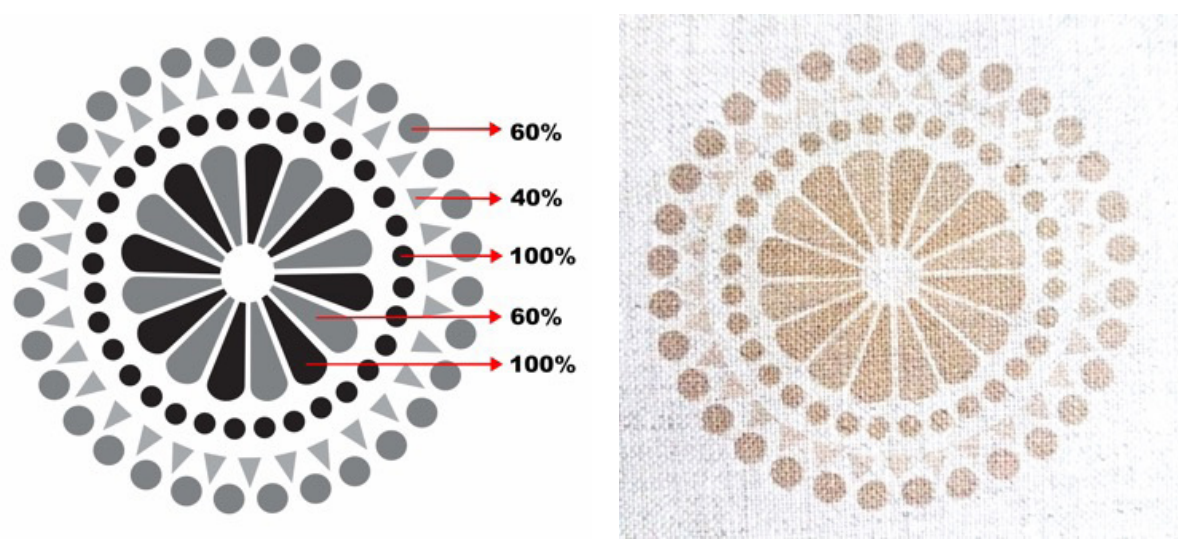

Fonte: Elaborado pelas autoras (2018).

De modo a avaliar e comparar os resultados finais obtidos até esta etapa, algumas amostras de tecido de linho com e sem gravação foram analisadas quanto à resistência à tração. Tendo como intenção principal deste artigo uma alternativa sustentável no desenvolvimento de produtos de moda, considerou-se necessária a verificação do comportamento do tecido após a gravação a laser realizada com os parâmetros eleitos via MEV, Microscópio Estereoscópico e análise visual e tátil. Primeiramente, foi realizada a caracterização mecânica dos corpos de prova contendo estampas corridas gravadas com potência $100 \%$ e velocidade $20 \mathrm{~m} / \mathrm{min}$, e dos corpos de prova sem gravação para fins de comparação (figura 10). 
Figura 10 - Dados do ensaio de tração do tecido de linho com gravação de estampa corrida com potência de $100 \%$ e velocidade de $20 \mathrm{~m} / \mathrm{min}$, e do tecido de linho sem gravação a laser (Oficina de Modelos e Protótipos/UFRGS).

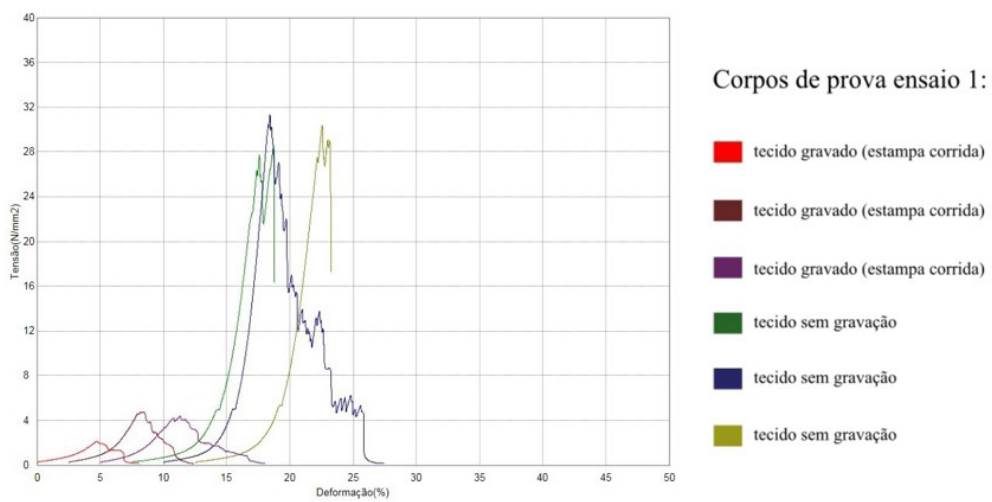

Fonte: Elaborado pelas autoras (2018).

Analisando as curvas tensão-deformação dos ensaios do linho com estampa corrida, observou-se que a resistência do tecido gravado $(2,5 \pm 5,0 \mathrm{~N} /$ $\mathrm{mm}^{2} ; 7,5 \pm 8,5 \%$ ) é consideravelmente inferior em relação ao tecido sem gravação a laser $\left(28,0 \pm 31,5 \mathrm{~N} / \mathrm{mm}^{2} ; 9,0 \pm 11,0 \%\right)$. Isto acontece, provavelmente, devido à degradação provocada pela queima do laser estar presente em toda extensão da amostra. A força atuante provoca o alongamento acentuado das fibras degradadas que estão presentes na seção transversal do tecido, tornando-o frágil para esforços mecânicos.

Posteriormente, foram submetidos ao ensaio corpos de prova não gravados e gravados com estampas localizadas possuindo dois diferentes parâmetros: potência de $100 \%$ e velocidade de $20 \mathrm{~m} / \mathrm{min}$; e potência de $50 \%$ e velocidade de $10 \mathrm{~m} / \mathrm{min}$ (figura 11). 
Projética, Londrina, v. 12, n. 2, p. 262-291, agosto 2021

Figura 11 - Dados do ensaio de tração do tecido de linho sem gravação e com gravação a laser de estampa localizada com os seguintes parâmetros: potência de $100 \%$ e velocidade de $20 \mathrm{~m} / \mathrm{min}$, e potência de $50 \%$ e velocidade de $10 \mathrm{~m} / \mathrm{min}$ (Oficina de Modelos e Protótipos/UFRGS).

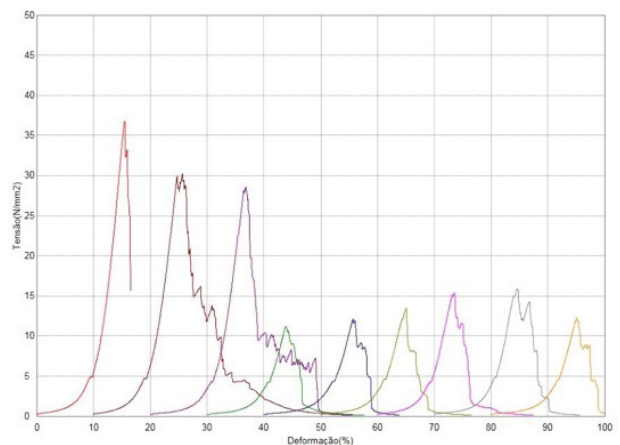

Fonte: Elaborado pelas autoras (2018).

Ao avaliar os resultados do ensaio de tração em tecido de linho para gravações a laser de estampas localizadas, constatou-se uma melhoria significativa na resistência do material em relação à estampa corrida. Ao deixar uma margem lateral (igual ou maior a 20\%) sem gravação nos quatro lados do tecido, os valores apresentados nas curvas de tensão-deformação chegam a crescer de duas a três vezes. Os resultados de resistência à tração do tecido sem estampa (36,0 $\pm 29,0 \mathrm{~N} /$ $\mathrm{mm} 2 ; 15,0 \pm 17,0 \%$ ) se aproximaram dos resultados dos corpos de prova gravados com estampa localizada (para potência de $100 \%$ e velocidade de $20 \mathrm{~m} / \mathrm{min}: 11,5 \pm$ $13,5 \mathrm{~N} / \mathrm{mm} 2 ; 14,0 \pm 15,5 \%$ e para potência de $50 \%$ e velocidade de $10 \mathrm{~m} / \mathrm{min}: 13,0$ $\pm 16,0$ N/mm2; 13,0 \pm 15,5\%). Em uma comparação dos diferentes parâmetros de gravação utilizados neste teste, foram obtidos valores mais satisfatórios com os tecidos de linho gravados com potência de $50 \%$ e velocidade de $10 \mathrm{~m} / \mathrm{min}$. 
Estamparia têxtil aplicada ao... linho ASSUNÇÃO, L. F.; MARTINEZ, A. K.; MARANTES, F. X.; et al.

\section{CONSIDERAÇÕES FINAIS}

Com este artigo buscou-se caracterizar e padronizar o processo de gravação a laser no tecido de linho para o desenvolvimento de produtos de moda sob enfoque sustentável.Com base nos resultados obtidos, torna-se possível constatar que a qualificação do processo de gravação a laser em tecidos, sobretudo em linho, pode ser extremamente útil para criação de estamparias em produtos de moda de forma ambientalmente amigável, sendo altamente viável a sua aplicação em escala industrial, em razão de sua rapidez e precisão.

Embora a gravação em tecido de linho seja monocromática, com o teste de escala tonal foi possível observar e apontar 03 tons diferentes da cor marrom (forte: 100\%, mediano: 80 ou 60\% e fraco: 40\%), que permitem a criação de estampas com efeitos diversos. No que se refere à avaliação detalhada dos traços retos e curvos, os resultados mostraram a gravação de linhas bem definidas e formas fielmente reproduzidas, revelando uma ampla possibilidade no desenvolvimento de desenhos para estampas. Em relação à qualificação do espaçamento entre linhas gravadas a laser em linho, os testes indicam que é necessária uma distância mínima de 0,5mm para que não ocorra interferência entre as linhas e sobreposição das mesmas. Além disso, as análises dos resultados da interação do laser com o tecido de linho possibilitaram a identificação dos parâmetros mais satisfatórios, os quais podem ser atingidos com a utilização da lente de $30 \times 30 \mathrm{~cm}$, potência de $50 \%$, velocidade de $10 \mathrm{~m} / \mathrm{min}$ em estampas localizadas com, no mínimo, 20\% de margem lateral sem gravação.

Os resultados apresentados configuram uma alternativa para a indústria têxtil que, em busca de um caminho de menor impacto, começa a direcionar seus esforços para modelos ambiental e socialmente orientados. No entanto, o estudo do processo de gravação a laser em materiais, bem como a avaliação da utilização 
Projética, Londrina, v. 12, n. 2, p. 262-291, agosto 2021

de tecido de linho na indústria da moda, é ainda um vasto campo a ser explorado. Além dos resultados aqui apresentados, indica-se a realização de pesquisas mais aprofundadas, principalmente no que diz respeito à análise conjunta destes temas visando produtos de melhor qualidade e mais longevos. O tecido de linho apresentou-se como um material com grande potencial para a aplicabilidade da gravação a laser. Neste sentido, sugere-se em trabalhos futuros, um estudo detalhado quanto a sua usabilidade (testes de lavagem, secagem, passadoria e ação do tempo, por exemplo) a fim de caracterizar as condições de manuseio das peças pelos usuários. 
Estamparia têxtil aplicada ao... linho ASSUNÇÃO, L. F.; MARTINEZ, A. K.; MARANTES, F. X.; et al.

Os resultados apresentados configuram uma alternativa para a indústria têxtil que, em busca de um caminho de menor impacto, começa a direcionar seus esforços para modelos ambiental e socialmente orientados.

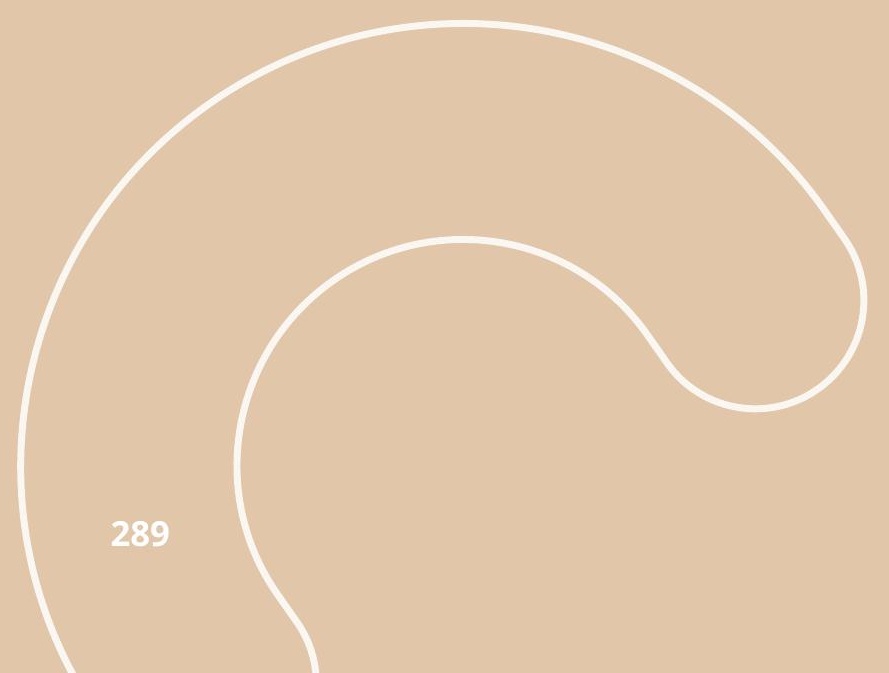


Projética, Londrina, v. 12, n. 2, p. 262-291, agosto 2021

\section{REFERÊNCIAS}

1. ASSOCIAÇÃO BRASILEIRA DA INDÚSTRIA TÊXTIL E DE CONFECÇÃO. Muito mais força para o setor e para o Brasil. São Paulo: ABIT, [2018?]. Disponível em: https://www.abit.org.br/cont/quemsomos. Acesso em: 12 ago. 2018.

2. ASSOCIAÇÃO BRASILEIRA DE NORMAS TÉCNICAS. NBR 11912: Materiais têxteis - Determinação da resistência à tração e alongamento de tecidos planos (tira). Rio de Janeiro: ABNT, 2016.

3. BAGNATO, Valderlei Salvador. Laser e suas aplicações em ciência e tecnologia. São Paulo: Editora Livraria da Física, 2008.

4. FARRER, Joan; WATT, Carolyn. Flax: sustainability is the new luxury. In: GARDETTI, Miguel; MUTHU, Subramanian (org.). Handbook of sustainable luxury textiles and fashion. Singapore: Springer, 2015. p. 19-41.

5. FERRERO, Franco et al. Surface degradation of linen textiles induced by laser treatment: comparison with electron beam and heat source. Autex Research Journal, Lodz, v. 2, n. 3, p. 109-114, Sept. 2002.

6. FLETCHER, Kate. Sustainable fashion and textiles: design journeys. New York: Routledge, 2014.

7. GWILT, Alisson. Moda Sustentável: um guia prático. São Paulo: Gustavo Gili, 2014.

8. HANN, Adelina. Innovation in Linen Manufacture. Textile Progress, [s. I.], v. 37, n. 3, p. 1-42, 2005.

9. HAN, Adelina; GUBENCU Dinu. Analysis of the laser marking technologies. Nonconventional Technologies Review, [s. I.], n. 4, p. 17-22, 2008.

10. KHAN, Sana; MALIK, Abdul. Environmental and health effects of textile industry wastewater. In: MALIK, Abdul; GROHMANN, Elisabeth; AKHTAR, Rais (org.). Environmental deterioration and human health. Dordrecth:

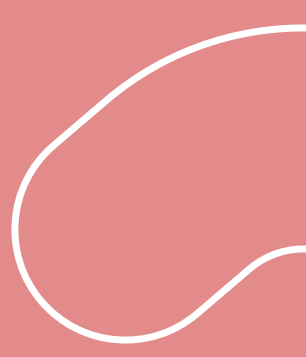
Springer, 2014. p. 55-71. 
Estamparia têxtil aplicada ao... linho ASSUNÇÃO, L. F.; MARTINEZ, A. K.; MARANTES, F. X.; et al.

11. KVAVADZE, Eliso et al. 30,000 Years old wild flax fibers: testimony for fabricating prehistoric linen. Science, [s. I.], v. 325, n. 5946, p. 1-3, Jan. 2009.

12. MATTHEWS, Janette. Textiles in Three Dimensions: An investigation into processes employing laser technology to form design-led three- dimensional textiles. 2011. Tese (Doutorado em Filosofia) - Loughborough University, Loughborough, 2011.

13. SALCEDO, Elena. Moda ética para um futuro sustentável. São Paulo: Editorial Gustavo Gilli, 2014.

14. SALMON-MINOTTE, Jack; FRANCK, Robert. Flax. In: FRANCK, Robert (org.). Bast and other plant fibers. Cambridge: Woodhead Publishing Limited and CRC Press, 2005. p. 94-176.

15. SAXENA, Sujata; RAJA, Amar; ARPUTHARAJ, Anuprabha. Challenges in sustainable wet processing of textiles. In: MUTHU; Subramanian (ed.) Textiles and clothing sustainability: textile science and clothing technology. Singapore: Springer, 2017. p. 43-79.

16. THOMPSON, Rob. Prototyping and low-volume production (the manufacturing guides). [S. I.]: Thames \& Hudson, 2011.

17. TROTEC. The power consumption of a laser machine. Disponível em:https:// www.troteclaser.com/en/knowledge/faqs/laser-power-consumption/. Acesso em: 13 jun. 2020.

18. YUAN, Guoxiang et al. Application of Laser engraving for sustainable fashion design. Research Journal of Textile and Apparel, Bingley, v. 17, n. 2, p. 21$27,2013$.

19. YUAN, Guoxiang; CHEN, Zhuoming; LUZZI, Domenico. Application of laser engraving for sustainable fashion design. In: CHOW, Pui-Sze et al. (org.). Contemporary Case Studies on Fashion Production, Marketing and Operations. Hong Kong: Springer, 2018. p. 43-59. 